\title{
Resposta de pastagens perenes à adubação com chorume suíno: cultivar Tifton 85
}

\section{Simone Meredith Scheffer-Basso ${ }^{1}$, Marcelo de Faria Ellwanger ${ }^{2}$, Clênio Valdeni Scherer ${ }^{3}$, Roberto Serena Fontaneli ${ }^{1}$}

\author{
1 Universidade de Passo Fundo. \\ 2 Avipal. \\ ${ }^{3}$ Secretaria da Agricultura de São Sepé, RS
}

RESUMO - O trabalho foi conduzido com o objetivo de verificar a resposta de uma pastagem de capim-tifton à adubação com chorume suíno (CS). O chorume suíno foi aplicado após os cortes em 15/10/2003 (emparelhamento), 24/11/2003, 10/1/2004 e 25/2/2004 nas doses de: 0, 15, 30 e 45 m³/ha/corte, totalizando 0, 60, 120 e $180 \mathrm{~m}^{3} /$ ha na primavera-verão. Em 10/4/2004, foi realizado o último corte, quando não foi mais aplicado chorume suíno. A maior produção de MS (2.232 kg/ha) foi obtida no segundo corte (janeiro de 2004), com $30 \mathrm{~m}^{3} / \mathrm{ha}$, 347\% superior à obtida sem aplicação de chorume suíno. A resposta da produção total de MS à adubação com chorume suíno foi quadrática e resultou em produções de 1.397 (sem CS), $2.971\left(15 \mathrm{~m}^{3}\right), 4.696\left(30 \mathrm{~m}^{3}\right)$ e $4.714\left(45 \mathrm{~m}^{3}\right) \mathrm{kg} / \mathrm{ha}$. A eficiência $\left(24,5 \mathrm{~kg} \mathrm{MS} / \mathrm{m}^{3} / \mathrm{ha}\right)$ do chorume suíno não diferiu entre as doses aplicadas, mas variou de 5,6 a $49,7 \mathrm{~kg} \mathrm{MS} / \mathrm{m}^{3} / \mathrm{ha}$ entre os cortes. A extração máxima de nitrogênio foi de $28 \mathrm{~kg} \mathrm{~N} / \mathrm{ha}\left(30 \mathrm{~m}^{3}\right.$ ) e a recuperação de nitrogênio variou de $2 \%$ (quarto corte) a 12\% (segundo corte). Os teores de PB e FDA foram afetados pela aplicação de chorume suíno e pela data de corte e variaram de 8,3 (sem chorume) a 10,7\% $\left(30 \mathrm{~m}^{3}\right)$ no primeiro corte e de 45,9 (sem chorume) a 42,8\% (45 $\left.\mathrm{m}^{3}\right)$ no último corte. A aplicação de chorume suíno é uma alternativa para aumentar a produção de pastagens de capim-tifton 85. Sugere-se a dose de $30 \mathrm{~m}^{3} /$ ha como valor-referência para aplicação depois de cada corte ou pastejo.

Palavras-chave: composição química, Cynodon, dejetos, nitrogênio

\section{Response of perennial pasture to fertilization with pig slurry: cv. Tifton 85}

ABSTRACT - The work was carried out with the aim to verify the response of a cv. Tifton 85 pasture, in Depressão Central of Rio Grande do Sul state, to pig slurry (PS) fertilization, in the rates of $0,15,30$ and $45 \mathrm{~m}^{3} / \mathrm{ha} /$ cutting, between October/03 and February/04, totalizing 0, 60, 120 e $180 \mathrm{~m}^{3} /$ ha in the spring-summer. The PS was applied after cuttings, in: 15/10/2003 (uniformizing cutting), 11/24/2003, 1/10/2004 and 2/5/2004. The last cut was done in 4/10/2004 and then it was not applied PS. The highest production (2,232 kg DM/ha) was obtained in the second cutting (January/2004), with $30 \mathrm{~m}^{3} /$ ha, a $347 \%$ higher than control. The total DM production response as function to PS was quadratic, being obtained 1,397 (without PS), 2,971 $\left(15 \mathrm{~m}^{3}\right), 4,696\left(30 \mathrm{~m}^{3}\right)$ and 4,714 $\left(45 \mathrm{~m}^{3}\right) \mathrm{kg} / \mathrm{ha}$. The PS efficiency did not differ between the rates $\left(24,5 \mathrm{~kg} \mathrm{DM} / \mathrm{m}^{3} / \mathrm{ha}\right.$ ) but it varied between cuttings, from 5.6 a $49.7 \mathrm{~kg} \mathrm{DM} / \mathrm{m}^{3} / \mathrm{ha}$. The highest $\mathrm{N}$ extraction was $28 \mathrm{~kg} \mathrm{~N} / \mathrm{ha}\left(30 \mathrm{~m}^{3}\right)$ and the $\mathrm{N}$ recovery varied from 2\% (fourth cutting) to 12\% (second cutting). The CP and ADF content were affected by fertilization and cutting date, varying between 8.3 (without CS) to $10.7 \%\left(30 \mathrm{~m}^{3}\right)$ in the first cutting and 45.9 (without PS) to $42.8 \%\left(45 \mathrm{~m}^{3}\right)$ in the last cutting, respectively. The PS application is an alternative to increase the pasture production of $\mathrm{cv}$. Tifton 85 , being suggested the $30 \mathrm{~m}^{3} / \mathrm{ha} /$ cutting as reference-value.

Key Words: chemical composition, Cynodon, manure, nitrogen

\section{Introdução}

Os primeiros estudos sobre o uso de dejetos em plantas forrageiras no Brasil foram realizados na Universidade Federal de Santa Maria, em pastagem natural, onde foram obtidos aumentos de até 307\% na produção de massa seca (MS) com aplicações repetidas de dejetos
( $40 \mathrm{~m}^{3} / \mathrm{ha}$ ), ao passo que, no centro do País, com aplicações de $150 \mathrm{~m}^{3} / \mathrm{ha} / \mathrm{ano}$, a produção de Brachiaria brizantha cv. Marundu, chegou a $156 \%$ a mais em relação à testemunha (Konzen, 2003). Com esse mesmo cultivar, Medeiros et al. (2007) concluíram que a aplicação de $180 \mathrm{~m}^{3}$ /ha/ano de dejetos líquidos de suínos, fermentados ou in natura, possibilita a obtenção de elevadas 
produções de MS, similares às obtidas com adubo mineral.

Uma das limitações do uso dos dejetos em culturas e pastagens é que, em razão da baixa e variada concentração de nutrientes, é necessário aplicar quantidades superiores às dos fertilizantes minerais para suprir as exigências nutricionais das plantas. Normalmente, o nitrogênio é o principal elemento adotado na determinação das doses de chorume a serem aplicadas, mas, se utilizado em excesso, pode ocasionar acúmulo de nitrato, tanto nas plantas como nos mananciais (Rogers et al., 1996). O índice de disponibilização de nitrogênio do chorume suíno é de 0,8 para o primeiro cultivo (SBCS, 2004).

As pastagens formadas com grama-bermuda e seus híbridos (Cynodon spp.) têm elevada capacidade de recuperação de nitrogênio do solo, pois a MS produzida é o principal determinante de absorção desse elemento (Brinck et al., 2003). Em grama-bermuda, em capim-pangola (Digitaria decumbens Stent) e capim-tanzânia (Panicum maximum Jacq.), o chorume suíno (CS) afeta os teores de nitrogênio, fósforo, proteína bruta, fibra em detergente neutro e fibra em detergente ácido (Zanine et al., 2004; Zanine et al., 2005). Em grama-bermuda fertilizada com efluentes de dejetos de suínos, Rogers et al. (1996) observaram que a concentração de proteína bruta aumentou com a aplicação de chorume suíno em dose de nitrogênio equivalente a $846 \mathrm{~kg} / \mathrm{ha}$. Adeli et al. (2005) aplicaram chorume suíno nas doses de 0, 50, 150 e $200 \mathrm{~m}^{3} /$ ha nessa espécie e observaram que o benefício mínimo de nitrogênio no solo foi obtido com dose superior a $100 \mathrm{~m}^{3}$ /ha, no verão.

Este trabalho foi realizado com o objetivo de avaliar a resposta de uma pastagem de capim-tifton 85 (Cynodon dactylon L. (Pers) $\times$ C. nlemfuensis Vanderyst) à aplicação de chorume suíno com a finalidade de determinar um valor-referência.

\section{Material e Métodos}

O experimento foi conduzido na Fazenda Timbaúva, em São Sepé, Rio Grande do Sul, no período de outubro de 2003 a abril de 2004, em uma área de pastagem de capimtifton 85 . O município está localizado a $30^{\circ} 10^{\prime} \mathrm{S}$ e $53^{\circ} 33^{\prime} \mathrm{O}$, a 85 m de altitude, na região fisiográfica da Depressão Central, onde o clima (Figura 1) é subtropical úmido tipo Cfa2 (Moreno, 1961). O solo pertence à Unidade de Mapeamento Vacacaí e caracteriza-se pela textura superficial franco-arenosa no horizonte A e pelo baixo teor de matéria orgânica (Tabela 1). Em 24/11/2003, foram realizadas aplicações superficiais de calcário dolomítico (2 t/ha), $\mathrm{P}_{2} \mathrm{O}_{5}$ na forma de superfosfato triplo (110 kg/ha) e $\mathrm{K}_{2} \mathrm{O}$ na

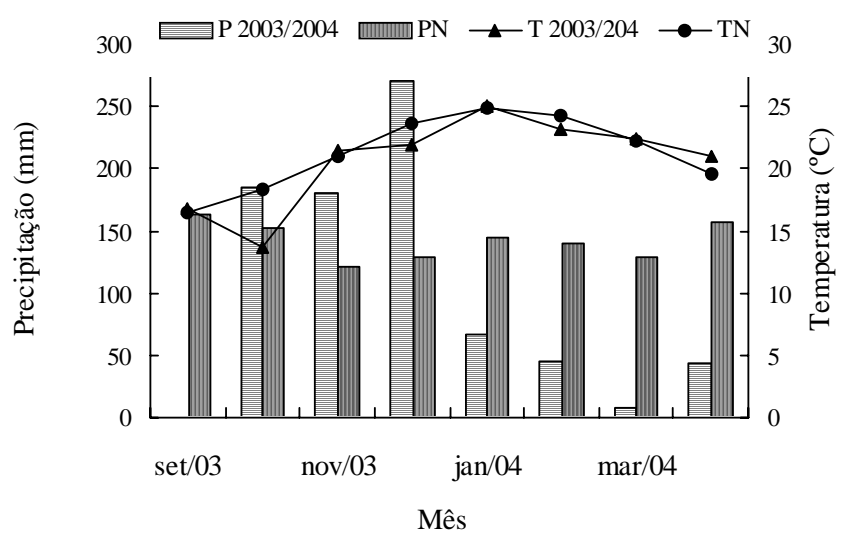

Figura 1 - Precipitação $(P)$ e temperatura média $(T)$ mensais no período experimental e as normais regionais ( $\mathrm{PN} ; \mathrm{TN})$. Fonte: INMET.

Tabela 1 - Atributos do solo na ocasião de implantação do ensaio

\begin{tabular}{lc}
\hline Atributo & Teor \\
\hline Argila & $11 \%$ \\
pH em água & 5,2 \\
P & $5,0 \mathrm{mg} / \mathrm{dm}^{3}$ \\
K & $76,0 \mathrm{mg} / \mathrm{dm}^{3}$ \\
Matéria orgânica & $1,3 \%$ \\
Al & $0,4 \mathrm{Cmol}_{\mathrm{c}} / \mathrm{dm}^{3}$ \\
Ca & $0,8 \mathrm{Cmol}_{\mathrm{c}} / \mathrm{dm}^{3}$ \\
Mg & $0,9 \mathrm{Cmol}_{\mathrm{c}} / \mathrm{dm}^{3}$ \\
$\mathrm{H}+\mathrm{Al}$ & $3,50 \mathrm{Cmol} / \mathrm{dm}^{3}$ \\
CTC & $5,30 \mathrm{Cmol} / \mathrm{dm}$ \\
Saturação de bases & $35 \%$ \\
Saturação de Al & $18 \%$ \\
\hline
\end{tabular}

forma de cloreto de potássio (80 kg/ha), após roçada de emparelhamento.

O trabalho consistiu da comparação de quatro doses de chorume suíno $\left(0,15,30\right.$ ou $\left.45 \mathrm{~m}^{3} / \mathrm{ha}\right)$ como fonte de nitrogênio em substituição à uréia, aplicadas depois de cada corte da pastagem. As doses de chorume suíno foram alocadas em delineamento de blocos casualizados, com quatro repetições, no qual as parcelas mediram $18 \mathrm{~m}^{2}$ $(6 \mathrm{~m} \times 3 \mathrm{~m})$, distantes $1,5 \mathrm{~m}$ entre si.

O chorume foi oriundo de uma unidade de terminação de suínos existente na propriedade, onde era armazenado em bioesterqueiras abertas revestidas com manta asfáltica de $8 \mathrm{~mm}$ de espessura. $\mathrm{Na}$ análise do dejeto, obtiveram-se os seguintes resultados: $\mathrm{N}=0,50 \% ; \mathrm{P}_{2} \mathrm{O}_{5}=0,37 \% ; \mathrm{K}_{2} \mathrm{O}=$ $0,30 \% ; \mathrm{pH}=7,7$; densidade $=1.025$ a $1.026 \mathrm{~kg} / \mathrm{m}^{3} ;$ e $5,11 \mathrm{~kg} / \mathrm{m}^{3}$ de nitrogênio. Dessa forma, com as doses de 15, 30 e $45 \mathrm{~m}^{3} / \mathrm{ha}$, foram aplicados 76,8; 153,7 e 230,5 kg de N/ha/corte. Considerando as quatro aplicações, no emparelhamento da pastagem e após os três primeiros cortes, foram aplicadas 
doses de chorume suíno de 60, 120 e $180 \mathrm{~m}^{3}$ /ha, que, em quantidade de nitrogênio, totalizaram 307,2; 614,8 e $922 \mathrm{~kg} / \mathrm{ha}$, respectivamente. Tendo em vista o índice de disponibilização de 0,8 , no primeiro cultivo (SBCS, 2004), essas quantidades representaram, em nitrogênio, 244,8; 491,2 e $736 \mathrm{~kg} / \mathrm{ha}$ para as três doses.

O chorume suíno foi aplicado após os cortes da pastagem, em: 15/10/2003 (corte de emparelhamento), 24/11/2003, 10/1/2004 e 25/2/2004. Em 10/4/2004, foi realizado o último corte, quando não foi mais aplicado o chorume suíno. As aplicações do fertilizante foram feitas pela manhã, após homogeneização (na própria esterqueira), coleta, transporte até o local do experimento e amostragem para a verificação da densidade.

Os cortes foram realizados com roçadeira costal a $10 \mathrm{~cm}$ da superfície do solo. Antes de cada corte, mediu-se a altura da pastagem e, em seguida, demarcou-se uma área de $1 \mathrm{~m}^{2}$ $(0,5 \times 2 \mathrm{~m})$ no centro da parcela, para coleta, pesagem da massa verde e retirada de subamostras de aproximadamente 500 g. As parcelas foram, então, roçadas e o restante do material foi retirado com auxílio de ancinhos. As subamostras, depois de pesadas, foram colocadas em estufa de ventilação forçada a $60^{\circ} \mathrm{C}$, durante 72 horas. Após a secagem, as amostras foram pesadas, trituradas em moinho tipo Willey e submetidas à análise para determinação dos teores de PB, FDA e FDN, pelo método de espectrometria de reflectância no infravermelho proximal (NIRS), cuja curva de calibração foi desenvolvida no Laboratório de Nutrição Animal do Centro de Pesquisa em Alimentos da Universidade de Passo Fundo. Foram calculados a quantidade de nitrogênio extraído pela pastagem $($ Nextr $=$ MS $\times$ quantidade de nitrogênio na MS), o percentual de recuperação do nitgrogênio $\left(\mathrm{RN}=100 \times\left[\left(\mathrm{Nextr}_{\mathrm{D} 15 / \mathrm{D} 30 / \mathrm{D} 45}-\mathrm{Nextr}_{\mathrm{D} 0}\right) /\right.\right.$ nitrogênio aplicado], segundo Primavesi et al. (2004), e a eficiência do chorume (EC $=\mathrm{MS}_{\mathrm{D} 15, / 30 / 45}-\mathrm{MS}_{\text {testemunha }} /$ chorume). Os dados foram submetidos à análise da variância, com posterior análise de regressão, utilizando-se o modelo de parcela subdividida no tempo, no qual as doses compuseram a parcela principal e os cortes, as subparcelas. Para comparação das médias obtidas nas datas de cortes, utilizou-se o teste de Tukey a 5\% de significância. A análise estatística foi realizada por meio do Programa SISVAR.

\section{Resultados e Discussão}

A aplicação do chorume suíno promoveu aumento na altura (Figura 2) e na produção de MS (Figura 3), em diversas grandezas e tendências, que variaram conforme a date de corte.

Os melhores resultados, independentemente da dose, foram obtidos no segundo corte, provavelmente em razão

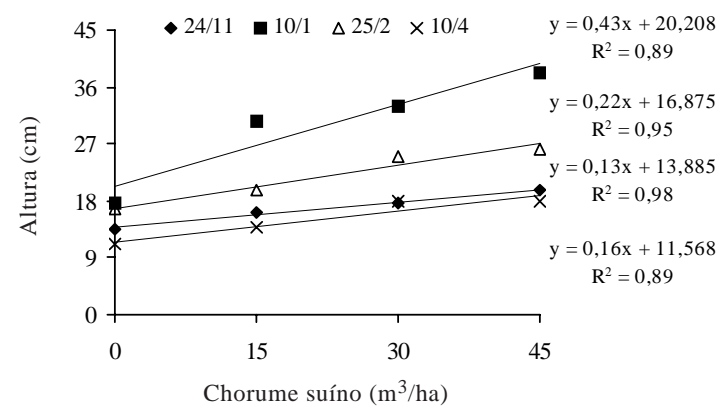

Figura 2 - Altura, em quatro datas de corte, de uma pastagem de capim-tifton 85 adubada com chorume suíno.

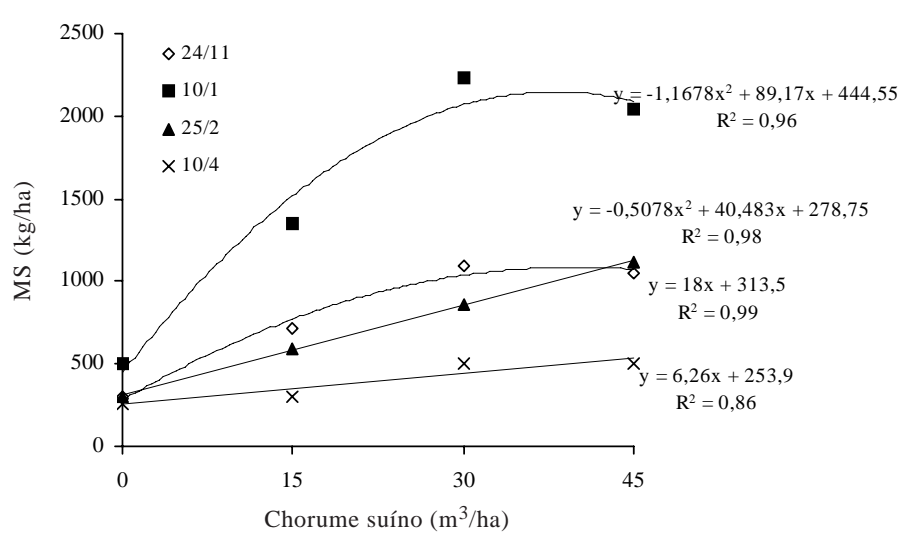

Figura 3 - Produção de massa seca, em quatro datas de cortes, de uma pastagem de capim-tifton 85 adubada com chorume suíno.

das adequadas condições de temperatura e precipitação (Figura 1). No período que antecedeu esse corte, que coincidiu com a época em que a pastagem estava em estádio vegetativo, choveu cerca de $270 \mathrm{~mm}$. Em março, no entanto, antes do último corte, choveu apenas $8 \mathrm{~mm}$. A precipitação pluviométrica entre janeiro e abril correspondeu a $28 \%$ da normal regional e se mostrou desfavorável à espécie e ao aproveitamento do fertilizante. Além disso, as temperaturas reduziram - o que comumente ocorre no outono no Sul do Brasil - diminuindo o crescimento da pastagem.

Menor efeito do chorume suíno no final da estação de crescimento também foi verificado em Brachiaria radicans Napper, por Mukul et al. (2002), no México. Larbi et al. (1990), na Flórida, também evidenciaram redução na produção de Cynodon spp. no outono em resposta à diminuição do fotoperíodo e da intensidade luminosa. Do mesmo modo, Adeli et al. (2005) não obtiveram resposta da grama-bermuda à adubação com chorume suíno no final da estação de crescimento e enfatizaram o maior risco de 
contaminação do solo, em virtude da pouca absorção do fertilizante nessa época do ano. Segundo esses autores, é importante melhorar a utilização e assimilação do nitrogênio aplicado por meio de chorume suíno. Para isso, a melhor prática é a aplicação do adubo no início da estação de crescimento.

Na média dos cortes, as doses de 15, 30 e $45 \mathrm{~m}^{3}$ de chorume suíno aumentaram 118, 245 e 247\%, respectivamente, a produção de matéria seca. No entanto, esses aumentos em comparação à não-aplicação de chorume suíno variaram entre os períodos de rebrota (Figura 3). No segundo corte, a produção obtida sem adubo correspondeu a 22,4\% daquela encontrada com as duas maiores doses de chorume suíno. No último período, no entanto, quando as condições de umidade foram desfavoráveis, essa relação foi de 53\%, o que induziu menor resposta à aplicação de chorume. Medeiros et al. (2007) também obtiveram respostas diferenciadas na produção de matéria seca de capimmarandu fertiirrigado com chorume suíno, em razão da pluviosidade.

A eficiência do chorume e do equivalente em nitrogênio não diferiu entre as doses (média de 24,5 kg MS/ $\mathrm{m}^{3} / \mathrm{ha}$ ), mas variou entre os cortes, comprovando o efeito das condições ambientais sobre a resposta ao fertilizante. Houve redução de 88,6\% da maior (segundo corte) para a menor eficiência (último corte). Medeiros et al. (2007), com aplicação única de chorume suíno (180 m³/ha), verificaram conversão de aproximadamente $67 \mathrm{~kg} \mathrm{MS} / \mathrm{m}^{3} / \mathrm{ha}$ considerando total de $12.090 \mathrm{~kg} \mathrm{MS} / \mathrm{ha}$ obtidos em quatro cortes.

Neste trabalho, no índice de disponibilização de 0,8 (SBCS, 2004), a eficiência do nitrogênio foi de $12 \mathrm{~kg} \mathrm{MS} / \mathrm{kg}$ (Tabela 2). Sabe-se que esse índice varia de acordo com as condições da pastagem e do clima. No cv. Coastcross adubado com fertilizante nitrogenado mineral, Alvim et al. (1998) estimaram entre 19 e 43 kg MS/kg de N na estação chuvosa, ao passo que, na época seca, a eficiência do nitrogênio foi de 14,8 a 32,1 kg MS/kg, comprovando que nessa situação o potencial da espécie é limitado.

A produção de matéria seca, em relação ao tempo de aplicação do chorume e ao total da estação, foi similar entre

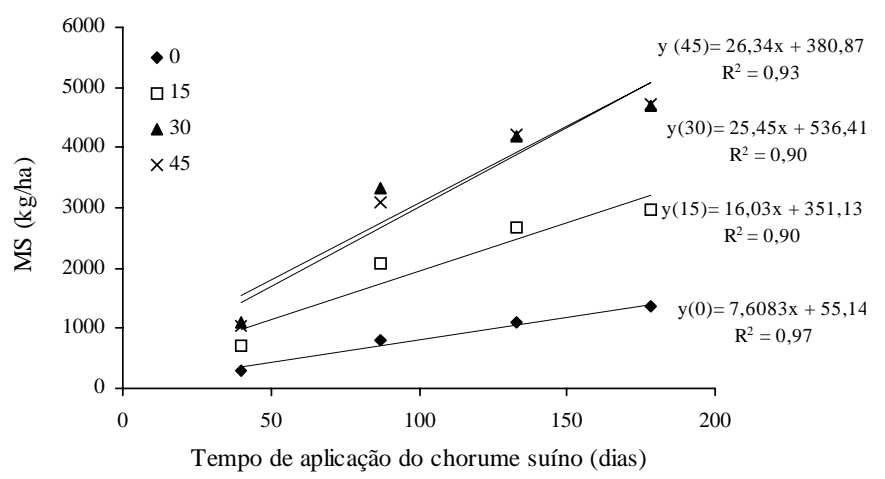

Figura 4 - Produção acumulada de massa seca (MS) de capimtifton 85 adubado com quatro doses de chorume suíno.

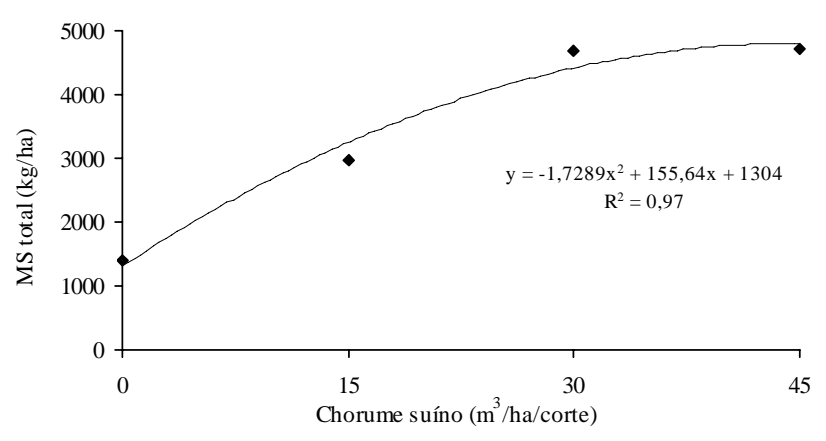

Figura 5 - Produção total de massa seca (MS) de capim-tifton 85 adubado com quatro doses de chorume suíno.

as duas maiores doses (Figuras 4 e 5). No total de matéria seca, os aumentos de MS representaram aumentos de $112 \%$ $\left(15 \mathrm{~m}^{3}\right), 235 \%\left(30 \mathrm{~m}^{3}\right)$ e $237 \%\left(45 \mathrm{~m}^{3}\right)$, em comparação aos obtidos sem aplicação de chorume suíno, e indicaram que a dose $45 \mathrm{~m}^{3} / \mathrm{ha} /$ corte supera a capacidade de absorção e de aproveitamento da pastagem. Adeli et al. (2005) também verificaram resposta quadrática da produção de matéria seca de grama-bermuda à adubação nitrogenada, com um platô na dose equivalente a $450 \mathrm{~kg} \mathrm{~N} / \mathrm{ha}$, na qual foram obtidas produções de $8.200 \mathrm{~kg}$ MS/ha (com chorume) e $7.700 \mathrm{~kg} \mathrm{MS} / \mathrm{ha}$ (com adubo comercial).

Tabela 2 - Eficiência do chorume suíno (EFCS) e do equivalente em nitrogênio (EFN) em uma pastagem de capim-tifton em diversas datas de corte

\begin{tabular}{lcc}
\hline Data de corte & $\begin{array}{c}\text { Eficiência do chorume suíno } \\
\text { (kg de MS/ha/m } \text { de chorume) }^{3}\end{array}$ & $\begin{array}{c}\text { Eficiência do equivalente em nitrogênio } \\
\text { (kg de MS/ha/ kg de nitrogênio) }\end{array}$ \\
\hline $24 / 11 / 2003$ & $24,1 \mathrm{~b}$ & $4,7 \mathrm{~b}$ \\
$10 / 1 / 2004$ & $49,7 \mathrm{a}$ & $9,7 \mathrm{a}$ \\
$25 / 2 / 2003$ & $18,7 \mathrm{bc}$ & $3,6 \mathrm{bc}$ \\
$25 / 2 / 2004$ & $5,6 \mathrm{c}$ & $1,1 \mathrm{c}$ \\
\hline
\end{tabular}

Médias seguidas de mesma letra não diferem $(P>0,05)$ pelo teste Tukey. 
Normalmente, a resposta de gramíneas tropicais à adubação com doses crescentes de nitrogênio é quadrática. Alvim et al. (1998), em Juiz de Fora, obtiveram com o cultivar Coastcross sob cortes a cada seis semanas, 3.900 (sem adubação com nitrogênio) e 14.700 kg MS/ha (com adubação nitrogenada - $750 \mathrm{~kg} / \mathrm{ha}$ ) na estação chuvosa. No entanto, na estação seca, a produção variou de 1.800 a $7.900 \mathrm{~kg} / \mathrm{ha}$ de MS nos mesmos níveis de nitrogênio, comprovando o efeito do nitrogênio em diversas condições pluviométricas. Scheffer-Basso et al. (2008) obtiveram, no mesmo ano e local onde foi conduzido este trabalho, $4.549 \mathrm{~kg}$ MS/ha de uma pastagem natural, com a aplicação de $45 \mathrm{~m}^{3} /$ ha/corte, equivalente a menos de $4 \%$ de diferença entre as duas pastagens.

A similaridade no desempenho das duas pastagens remete à hipótese de que as condições climáticas limitaram mais a produção do cv. Tifton 85 , haja vista seu reconhecido e elevado potencial de produção de matéria seca. No entanto, é necessário determinar sua adaptação às condições edáficas, pois as gramas-bermudas e seus híbridos exigem solos férteis e, neste trabalho, o solo era arenoso e com baixos teores de matéria orgânica (Tabela 1). Na mesma região fisiográfica, porém em solo com o dobro de argila (22\%), com 3,3\% de matéria orgânica e com restrição hídrica em um dos períodos de rebrota, Scaravelli et al. (2007) obtiveram $10.700 \mathrm{~kg}$ de MS/ha com o cv. Coastcross-1.

A quantidade de nitrogênio extraída, obtida pelo produto da MS produzida e do teor desse elemento, variou entre os cortes, comprovando resposta positiva, porém com distintas tendências e grandezas, para as doses de chorume (Figura 6). Durigon et al. (2002) registraram 32 e $53 \mathrm{~kg} \mathrm{~N} / \mathrm{ha}$ em uma pastagem natural adubada com 20 e $40 \mathrm{~m}^{3}$ de chorume suíno, respectivamente, em um período de 45 dias. Neste estudo, o máximo ( $28 \mathrm{~kg} \mathrm{~N} / \mathrm{ha}$ ) foi obtido com $30 \mathrm{~m}^{3}$ de chorume suíno, conseqüência da limitada recuperação do nitrogênio, que, na média das doses, foi de $6,8 \%$, ao passo que entre os cortes variou de $2 \%$ (último corte) a $12 \%$ (segundo corte).

Ainda há muito pouca informação a respeito da eficiência dos dejetos como fertilizantes e de todas as variáveis analisadas nesses estudos, especialmente quanto aos limites de segurança ambiental. Rogers et al. (1996) recomendaram $448 \mathrm{~kg}$ N/ha na forma de chorume suíno para adubação de grama-bermuda, assumindo $50 \%$ de perda por volatilização, mas enfatizaram que as perdas de nitrogênio decorrentes de volatilização e desnitrificação variam com o método de aplicação, o tipo e a umidade do solo, a temperatura ambiental e a interação desses fatores. De modo geral, a dose a ser recomendada depende do potencial de absorção das espécies.

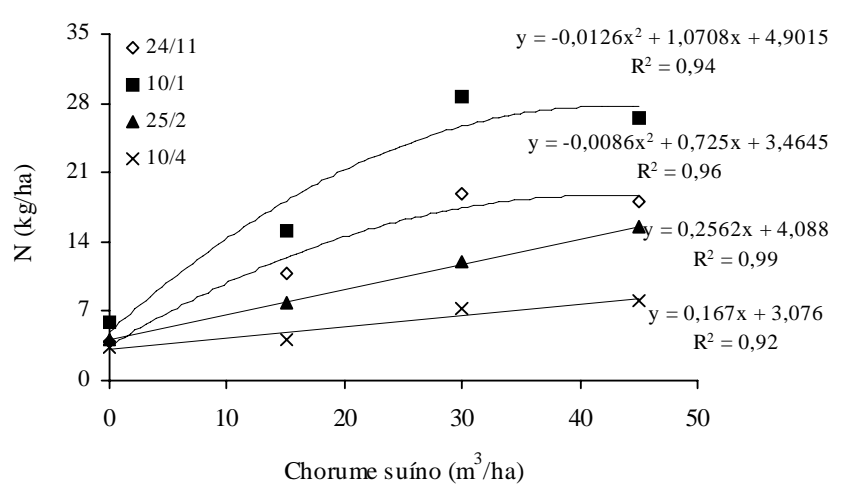

Figura 6 - Extração de nitrogênio, em quatro datas de corte, de uma pastagem de capim-tifton 85 adubada com chorume suíno.

A composição da pastagem variou de acordo com a dose de chorume suíno e a data de corte (Tabela 3 ). Em geral, o teor de $\mathrm{PB}$ respondeu positivamente $(\mathrm{y}=0,0322 \mathrm{x}+7,94)$ ao aumento da dose de chorume suíno, especialmente no primeiro e último cortes. Sem a aplicação de chorume suíno, os teores de PB não variaram ao longo da estação de crescimento, com amplitude de um ponto percentual, ao passo que, sob efeito do chorume suíno, a amplitude foi de 2,5 pontos percentuais. Adeli et al. (2005) obtiveram entre 14,8 e 18,3\% de PB em grama-bermuda adubada com chorume suíno em doses equivalentes a 115 e $665 \mathrm{~kg}$ de N/ha/ano, respectivamente. Ressalta-se que, nesse caso, o intervalo de cortes foi de quatro semanas, enquanto neste trabalho, foi de seis semanas, o que seguramente induziu à redução no teor de PB. Apesar disso, o conteúdo protéico obtido neste trabalho foi superior ao mínimo exigido por bovinos adultos em pastejo (Minson, 1981).

O teor de FDA reduziu com o aumento da dose de chorume suíno (y = -0,0198 + 42,79) e sofreu variação ao longo da estação de crescimento, com amplitudes de 6,1 (sem CS), 5,2 (15 m³), 5,4 (30 m³) e 3,8 $\left(45 \mathrm{~m}^{3}\right)$ pontos percentuais. Os resultados foram similares aos estimados por Adeli et al. (2005) e Alvim et al. (1998). O teor de FDN, no entanto, não foi afetado pela adubação e variou com a data de corte (Tabela 2). Rogers et al. (1996) também não verificaram efeito do chorume suíno no teor de FDN de grama-bermuda. Adeli et al. (2005), no entanto, estimaram redução de 56,8 e 53\% nesse componente sob aplicação de 115 e 665 kg N/ha/ano na forma de chorume suíno.

Os resultados deste trabalho ainda são preliminares e denotam a necessidade de mais informações sobre o assunto, mas são de grande importância para a região em estudo. A área de forragicultura é uma daquelas de maior potencial para o uso de chorume, no entanto, é essencial o 
Tabela 3 - Composição química da massa seca de uma pastagem de capim-tifton 85 adubada com quatro doses de chorume suíno

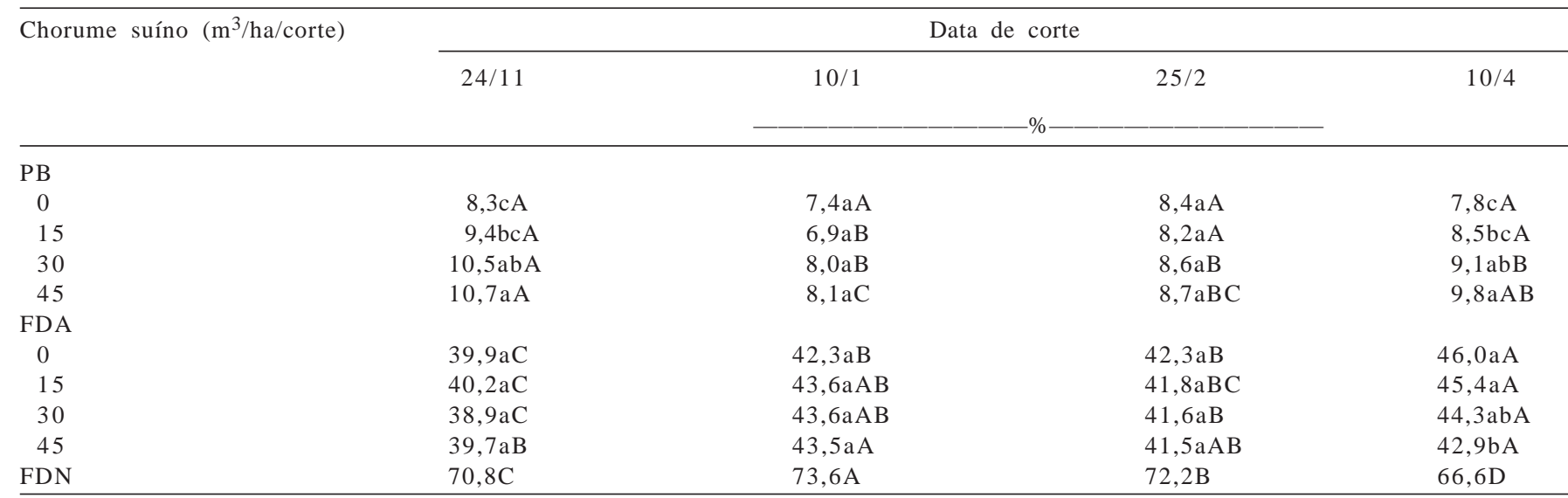

Médias seguidas de mesma letra minúscula, na linha, e maiúscula, na coluna, não diferem $(P>0,05)$ pelo teste Tukey.

desenvolvimento de estudos para a correta utilização dessa alternativa de adubação. Com os dados obtidos neste estudo, espera-se contribuir com projetos em andamento e enfatizar a importância de uma abordagem multidisciplinar, considerando a importância do monitoramento ambiental necessário a essa prática.

\section{Conclusões}

A aplicação de chorume suíno é uma alternativa válida para aumentar a produção de pastagens de capim-tifton 85 . Sugere-se como valor-referência a dose de $30 \mathrm{~m}^{3} /$ ha após corte ou pastejo. A eficiência do fertilizante é afetada pelas condições ambientais vigentes, portanto, sua aplicação deve ser realizada quando a pastagem está em vigoroso crescimento e com maior absorção de nutrientes e deve se restringir ao período do início da primavera até meados do verão, no sul do Brasil.

\section{Agradecimento}

Ao professor Irineu Fioreze, do Laboratório de Solos da Universidade de Passo Fundo, pelas recomendações técnicas na etapa de coleta e análise dos dejetos, e ao professor João Dürr, pelo incentivo ao encaminhamento deste trabalho para publicação.

\section{Literatura Citada}

ADELI, A.; VARCO, J.J.; SISTANI, K.R. et al. Effects of swine lagoon effluent relative to commercial fertilizer application on warm-season forage nutritive value. Agronomy Journal, v.97, p.408-417, 2005.

ALVIM, M.J.; XAVIER, D.F.; BOTREL, M.A. et al. Resposta do coast-cross (Cynodon dactylon (L.) Pers.) a diferentes doses de nitrogênio e intervalos de corte. Revista Brasileira de Zootecnia, v.27, n.5, p.833-840, 1998.

BRINCK, G.E.; ROWE, D.E.; SISTANI, K.R. et al. Bermudagrass cultivar response to swine effluent application. Agronomy Journal, v.95, p.597-601, 2003.

DURIGON, R.; CERETTA, C.A.; BASSO, C.J. et al. Produção de forragem em pastagem natural com o uso de esterco líquido de suínos. Revista Brasileira de Ciência do Solo, v.26, p.983992, 2002.

KONZEN, E.A. Fertilização de lavoura e pastagem com dejetos de suínos e cama de aves. Sete Lagoas: Embrapa Milho e Sorgo, 2003. 19p. (Informe Técnico).

LARBI, A.; MISLEVY, P.; ADJEI, M.B. et al. Seasonal herbage and animal production from three Cynodon species. Tropical Grasslands, v.24, p.305-31, 1990.

MEDEIROS, L.T.; REZENDE, A.V.; VIEIRA, P.F. et al. Produção e qualidade da forragem de capim-marandu fertiirrigada com dejetos líquidos de suínos. Revista Brasileira de Zootecnia, v.36, n.2, p.309-318, 2007.

MINSON, D.J. Effects of chemical and physical composition of herbage eaten upon intake. In: HACKER, J.B. (Ed.). Nutritional limits to animal production from pastures. St. Lucia: CSIRO, 1981. p.167-182.

MOREnO, J.A. O clima do Rio Grande do Sul. Porto Alegre: Secretaria da Agricultura, 1961. p.41.

MUKUL, R.R.G.; LARA, P.E.L.; GARCIA, J.R.S. Abonado del pasto tanner (Brachiaria radicans Napper) com purines: rendimiento de forraje y extracción de nutrimentos. Revista Técnica Pecuária en México, v.40, n.3, p.265-274, 2002.

PRIMAVESI, A.C.; PRIMAVESI, O.; CORRÊA, L.A. et al. Adubação nitrogenada em capim-coastcross: efeitos na extração de nutrientes e recuperação aparente do nitrogênio. Revista Brasileira de Zootecnia, v.33, n.1, p.88-78, 2004.

ROCHA, F.P.; EVANGELISTA, A.R.; LIMA, J.A. et al. Adubação nitrogenada em gramíneas do gênero Cynodon. Ciência Animal Brasileira, v.3, n.1, p.1-9, 2002.

ROGERS, J.R.; HARVEY, R.W.; POORE, M.H. et al. Application of nitrogen from swine lagoon effluent to bermudagrass pastures: seasonal changes in forage nitrogenous constituents and effects of energy and escape protein supplementation on beef cattle performance. Journal of Animal Science, v.74, p.1126-1133, 1996.

SCARAVELLI, L.F.B.; PEREIRA, L.E.T.; OLIVO, C.J. et al. Produção e qualidade de pastagens de Coastcross-1 e milheto utilizadas com vacas leiteiras. Ciência Rural, v.37, n.3, p.841-846, 2007. 
SCHEFFER-BASSO, S.M.; SCHERER, C.V.; ELWANGER, M. Resposta de pastagens perenes à adubação com chorume suíno: pastagem natural. Revista Brasileira de Zootecnia, v.37, n.2, p.221-227, 2008.

SOCIEDADE BRASILEIRA DE CIÊNCIA DO SOLO - SBCS. Manual de adubação e calagem para os Estados do Rio Grande do Sul e de Santa Catarina. Comissão de Química e Fertilidade do Solo: Comissão de Química e Fertilidade do Solo, 2004. 400p.

ZANINE, A.M.; DIAS, P.F.; ALMEIDA, J.C.C. et al. Rendimento de parte aérea e raiz e teores de nitrogênio e fósforo, em cultivares dos gêneros Digitaria e Cynodon, sob o efeito de doses de nitrogênio na forma de chorume bovino. In: REUNIÃO ANUAL DA SOCIEDADE BRASILEIRA DE ZOOTECNIA, 41., 2004, Campo Grande. Anais... Campo Grande: Sociedade Brasileira de Zootecnia, 2004a. (CD-ROM).

ZANINE, A.M.; SCHIMIDT, L.T.; DIAS, P.F. Efeito da aplicação de nitrogênio, sob a forma de chorume bovino, na qualidade e produção do pasto tanzânia (Panicum maximum). Seropédica: Embrapa Agrobiologia, 2005. 19p. (Documentos, 192). 